\title{
GÊNEROS TEXTUAIS E EDUCAÇÃO INICIAL DO PROFESSOR DE LÍNGUA INGLESA*
}

\author{
Vera Lúcia Lopes Cristovão**
}

Resumo: De acordo com os pressupostos teórico-metodológicos do interacionismo sociodiscursivo BRONCKART; MACHADO, 2004; BRONCKART, 2006; GUIMARAEES; MACHADO; COUTINHO, 2007), a relevância dos estudos de gêneros para a educação inicial está no fato de serem produtores de valores e de formas de agir sócio-historicamente situados. Os conjuntos de textos (de diferentes gêneros textuais), que circulam na formação inicial, configuram-se uma rede de discursos que ajudam a tecer o gênero profissional docente e, de alguma forma, contribuem para a aprendizagem profissional do futuro professor. Esses gêneros textuais se textualizam de diferentes modos nessa esfera da atividade social (BRONCKART, 2006). Assim, esta pesquisa propôs-se a (a) analisar as características de artigos de opinião produzidos por futuros professores e b) investigar o(s) perfil(is) de profissional que se constrói(em) discursivamente nos textos analisados. Os resultados apontam para um dominio relativamente baixo do gênero, mas representam importante espaço para reflexão sobre a esfera de atividade profissional escolbida.

Palavras-chave: Gêneros textuais. Educação inicial de professores. Artigo de opinião.

\section{INTRODUÇÃO}

A articulação entre práticas discursivas e a educação inicial por meio da compreensão e produção de textos que envolvem o "uso da linguagem" e a "situação de trabalho" enfoca a linguagem como orientadora das ações. Tendo como base o estudo de gêneros, parto do pressuposto de que a apropriação de gêneros textuais é salutar para a socialização e de que a inserção do indivíduo em práticas discursivas é crucial para a construção identitária. De acordo com os pressupostos teóricos do interacionismo sociodiscursivo (BRONCKART, 2006; GUIMARÃES; MACHADO; COUTINHO, 2007), a relevância dos

\footnotetext{
* Meus profundos agradecimentos à Profa. Dra. Maria Adelaide de Freitas pela leitura e pelas sugestões de alteração.

** Professora Adjunta da Universidade Estadual de Londrina, com Pós-doutorado em Linguística Aplicada e Estudos da Linguagem. Email: veracristovão@yahoo.com.
} 
estudos de gêneros para a educação inicial está no fato de serem produtores de valores e de formas de agir sócio-historicamente situados.

A fim de aprofundar as reflexões teóricas de questões que consideram as práticas de linguagem e o agir no trabalho, o estudo privilegia a educação inicial e a constituição do gênero profissional docente. Expõe Souza-e-Silva (2004, p. 97),

[...] o gênero da atividade, tomado neste artigo como equivalente a gênero profissional, fundamenta-se em um princípio de economia da ação; ele é, de algum modo, a parte subentendida da atividade, aquilo que os trabalhadores de um dado meio conhecem, esperam, reconhecem, apreciam; o que lhes é comum e o que os reúne sob condições reais de vida; o que eles sabem dever fazer sem que seja necessário reespecificar a tarefa cada vez que ela se apresenta. Existem tipos relativamente estáveis de atividades socialmente organizadas por um meio profissional, tipos por intermédio dos quais o mundo da atividade pessoal se realiza, se precisa em formas sociais que não são fortuitas, nem ocasionais, mas que têm razão de ser e uma certa perenidade.

$\mathrm{Na}$ verdade, os conjuntos de textos (de diferentes gêneros textuais) que circulam na formação inicial configuram-se como uma rede de discursos que ajudam a tecer o gênero profissional docente e, de alguma forma, contribuem para a aprendizagem profissional do futuro professor. Esses gêneros textuais se textualizam de diferentes modos nessa esfera da atividade social (BRONCKART, 2006).

$\mathrm{Na}$ área de língua materna, Matêncio (2008) pesquisou o papel do gênero na vinculação das práticas sociais às ações do sujeito e sua contribuição ao processo de construção identitária na formação do professor e para a construção de representações.

O artigo de opinião foi escolhido pela: a) reflexão sobre o funcionamento sociocomunicativo que o aluno, futuro professor, pode fazer; b) possibilidade de levar o aluno a se posicionar pela linguagem; e c) aprendizagem de mecanismos de textualização. Tal escolha tomou por base Matêncio (2008, p. 194), que afirma que "a textualização resulta do 'enquadre' dado, pelos sujeitos em interação, ao evento no qual atuam, o que vai levá-los a recuperar em sua memória esquemas de ação e a construir um modelo de representação da situação efetiva”. 
Assim, esta pesquisa propõe-se a (a) analisar características de artigos de opinião produzidos por alunos-professores de língua inglesa em seu processo de apropriação de tal gênero; (b) investigar o(s) perfil(is) de profissional que se constrói(em) (discursivamente) nos textos analisados .

Para tentar atingir esses objetivos, este artigo está dividido em três partes, em que exponho, sucessivamente, algumas considerações gerais sobre gêneros textuais e educação inicial, os procedimentos metodológicos de análise utilizados, os resultados dessa análise pertinentes às questões levantadas e, finalmente, as conclusões gerais.

\section{GÊNEROS TEXTUAIS E EDUCAÇÃO INICIAL}

De acordo com Machado (2004), os trabalhos podem ter diferentes focos - tais como as ferramentas de ensino, o aluno, o professor em formação ou o formador. Este estudo enfoca o uso de gêneros textuais como ferramentas no processo de educação inicial do professor de língua inglesa.

[...] nessa medida, pode-se ressaltar a importância de que o acesso dos professores em formação a textos de diferentes domínios discursivos seja sistematizado, sempre que possível, por atividades em que se vincule, explicitamente, o saber dizer ao saber fazer (MATÊNCIO, 2008, p. 196).

As orientações atuais - Diretrizes para a Formação Inicial de Professores da Educação Básica (BRASIL, 2002) - estabelecem como princípios norteadores a competência, como concepção nuclear, a coerência entre formação oferecida e prática esperada e a pesquisa. De acordo com Perrenoud (1999, p. 7-8), competência é "uma capacidade de agir eficazmente em um determinado tipo de situação, apoiada em conhecimentos, mas sem limitar-se a eles [...] as competências [...] utilizam, integram, ou mobilizam tais conhecimentos". Depois de esclarecer que competência não é o mesmo que objetivos, desempenho ou competência linguística, o autor afirma que ela está relacionada a "savoir-faire" e "recursos". Na concepção do autor, conhecimentos são 
"recursos cognitivos complementares, [...] representações da realidade, que construímos e armazenamos" (PERRENOUD, 1999, p. 7-8). O autor ainda retoma três tipos de conhecimentos propostos pelas ciências cognitivas como necessários às competências: os

[...] declarativos (descrevem a realidade sob a forma de fatos, leis, constantes ou regularidades); procedimentais (descrevem o procedimento a aplicar para obter algum tipo de resultado); condicionais (determinam as condições de validade dos conhecimentos procedimentais). (PERRENOUD, 1999, p. 8).

Outras pesquisas sobre o trabalho do professor tratam da identificação, reconhecimento e formação de domínios constitutivos da profissão docente. Revisões bibliográficas (ROSSI, 2004; BORGHI, 2006; CAMARGO, 2007), ${ }^{1}$ que discorrem sobre a terminologia adotada na literatura, apontam para conceitos que se referem a: a) professores em geral (SHULMAN, 1986,1987; TARDIF, 1994, 2002; FREEMAN; JOHNSON, 1998; PERRENOUD, 1999; SAUJAT, 2004; AMIGUES, 2004; PLACCO, 2005, 2006) e b) professores de línguas (CANALE; SWAIN, 1980; RICHARDS, 1998; ALMEIDA FILHO, 2000; LEFFA, 2006). Os conceitos dos especialistas citados variam de acordo com seu quadro teórico, sendo definidos como base de conhecimento, domínios de base de conhecimento, competências, capacidades, saberes, conhecimentos ou dimensões.

Richards (1998) aponta para saberes que envolvem a atividade docente do professor de LE, sendo eles:

a) conhecimento teórico, referente às teorias que incorporem não só pesquisas educacionais e seus autores, mas também princípios da abordagem reflexiva;

b) habilidade de ensinar, que envolva uma variedade de tarefas pedagógicas necessárias a qualquer professor, bem como habilidades específicas do professor de LE (ex. preparo de

\footnotetext{
${ }^{1}$ As referências são de dissertações de mestrado desenvolvidas no Programa de Pós-Graduação em Estudos da Linguagem da UEL.
} 
atividades comunicativas e correção dos erros de forma adequada);

c) habilidade comunicativa, relacionada às habilidades gerais de comunicação e proficiência linguística;

d) conhecimento prático (da matéria), que inclua a prática pedagógica, acadêmica e linguística;

e) argumentação pedagógica e tomada de decisão, que relacionem teoria e prática;

f) conhecimento contextual, referente à exigência dos fatores dos contextos social, político e físico, que inclua políticas da língua, valores culturais, tipos de escola, diferenças dos aprendizes e recursos para o ensino.

No cenário de documentos oficiais para formação inicial, as Diretrizes Curriculares Nacionais para Formação de Professores da Educação Básica (BRASIL, 2002) propõem diversas competências que se esperam desses profissionais, tais como:

a) as competências referentes à compreensão do papel social da escola;

b) as competências referentes ao domínio dos conteúdos a serem socializados, aos seus significados em diferentes contextos e a sua articulação interdisciplinar;

c) as competências referentes ao domínio pedagógico;

d) as competências referentes ao conhecimento de processos de investigação que possibilitem o aperfeiçoamento da prática pedagógica;

e) as competências referentes ao gerenciamento do próprio desenvolvimento profissional.

Segundo análise de Machado e Cristovão (2005) sobre as Diretrizes Curriculares para os cursos de Formação de Professores, essas competências se referem:

a) a um agir do professor em diferentes atividades coletivas, fora da sala de aula, junto a vários outros agentes, com finalidades preestabelecidas; 
b) a um agir individual a ser desenvolvido para a autoprescrição do trabalho em sala de aula;

c) ao agir no trabalho específico de sala de aula.

O estudo de Machado (2002) associa a institucionalização da lógica das competências no Brasil a um processo de "crescente homogeneização ideológica mundial”. Diante de uma realidade socioeconômica que demanda determinado funcionamento dos mercados de trabalho, o sujeito precisa estar re-qualificado para "dispor de estoques de recursos cognitivos, técnicos e relacionais e conseguir mobilizá-los, articulá-los e utilizá-los de modo operativo e eficaz na realidade prática do trabalho ou mesmo da vida social" (MACHADO, 2002, p. 93). A partir dessa noção de competência, a autora conclui que o processo busca a instrumentalização e a individualização das pessoas para atuar de forma produtiva na sociedade.

Para Nunes, Monteiro, Santos, Távora e Cunha (2005), o conceito de competência nos documentos oficiais da política de formação de professores no Brasil é posto como necessário "para a organização do ensino: dos conhecimentos a serem trabalhados, dos métodos a serem empregados e, sobremaneira, da avaliação a ser desenvolvida nos alunos dos cursos de formação de professores quer inicial ou continuada" (p. 5). A meu ver, subjacente está a noção de que quem sabe usar ou mobilizar recursos e saberes é um executor.

Este cenário me levou à busca de uma noção que se voltasse para aspectos do contexto sócio-histórico e para os diferentes aspectos característicos do trabalho do professor. $\mathrm{Na}$ área da educação, no contexto brasileiro, Placco $(2005,2006)$ conceitua dimensões da formação e do trabalho do professor. Essas dimensões, que são dialeticamente relacionadas umas com as outras, podem ser definidas como um conjunto atravessado pela ética e pela intencionalidade. Portanto, admite-se que o desenvolvimento do sujeito se dê em múltiplas dimensões que contribuem para a constituição do indivíduo. São elas: técnica ou técnico-científica, humano-interacional, política, da formação continuada, do trabalho coletivo, dos saberes para ensinar, críticoreflexiva, avaliativa, estética, cultural e ética. 
A dimensão técnica ou técnico-científica envolve os conhecimentos técnico-científicos da área de atuação do professor (o domínio do uso da língua, por exemplo) articulados às práticas de ensino e a outros saberes que contribuam para a prática efetiva de ensino/aprendizagem.

A dimensão avaliativa trata de conhecimentos da prática pedagógica (bases teóricas e fundamentos utilizados em seu exercício profissional como pesquisa, análise e proposta de resultados, por exemplo) e de questões relacionadas ao contexto de trabalho docente (diversos contextos interculturais, por exemplo).

A dimensão da formação continuada abrange o interesse e a motivação do profissional pelo constante aperfeiçoamento, pela pesquisa sobre sua área de trabalho e sobre a sociedade, bem como a participação em trabalho em rede/parcerias.

A dimensão dos saberes para ensinar diz respeito aos conhecimentos do professor sobre os objetos do processo de ensino/aprendizagem, sobre o uso de recursos didáticos em sala de aula, sobre métodos e abordagens, entre outros.

A dimensão do trabalho coletivo engloba o trabalho em cooperação por meio de projetos desenvolvidos na interação com profissionais de áreas diversas a fim de formar um aluno-cidadão.

$\mathrm{Na}$ dimensão crítico-reflexiva, considera-se a capacidade do profissional para conhecer seus processos cognitivos bem como para autorregulá-los por meio de atividades reflexivas relativas tanto à vida profissional quanto à pessoal.

A dimensão estética e cultural abrange experiências estéticas e culturais da formação do professor e a ação de promover esses contatos com diferentes formas de cultura entre os alunos, e pode instigar reflexões sobre questões de identidade e de respeito à diversidade.

No quadro de pesquisas mais recentes do ISD também tenho encontrado a adoção do conceito de dimensões como o proposto nas ciências do trabalho (SAUJAT, 2004; AMIGUES, 2004). Em sua pesquisa de mestrado, Borghi (2006), com base em Saujat (2004) e Amigues (2004), identifica diferentes dimensões do trabalho do professor em falas de professoras novatas durante a coleta de dados por meio de autoconfrontação simples. Algumas delas são: prescritiva, 
renormalizadora, material, temporal, profissional, cognitiva, didática, social, artística e identitária.

Diante dessa breve recensão, alinho-me à perspectiva das dimensões pelo fato de múltiplos fatores (externos à sala de aula) serem considerados constitutivos do agir docente. Assim, se o currículo do curso de Letras estiver orientado por uma concepção que não considere o professor como executor de tarefas para e na sala de aula, mas como um professor-pesquisador que investiga, planeja, cria, avalia, isto é, age num contexto situado e coconstruído por ele, o aluno, futuro profissional, estará continuamente discutindo e refletindo sobre seu trabalho como professor a fim de apreender um rol adequado de conhecimentos e desenvolver suas competências/dimensões. Para isso, todas as disciplinas deveriam abranger conteúdos comunicativos, temáticos, sistêmicos e metodológicos, ocorrendo simultaneamente no desenvolvimento das atividades pedagógicas e contribuindo, assim, para maior articulação entre teoria e prática (GIMENEZ; CRISTOVÃO, 2004).

Os fundamentos supracitados sustentam a realização de um projeto que enfoque práticas discursivas relevantes para o agir docente e atenda às necessidades do contexto, ao mesmo tempo que vêm romper com os tipos de formação cristalizados em torno da racionalidade técnica e da aprendizagem de certos tipos de competências que os limitariam ou privilegiariam a execução e não a construção do gênero de atividade.

Sob a perspectiva que adoto pela intervenção (no curso de Letras em que atuo), tenho em vista o objetivo de colaborar para a formação de professores com autonomia e emancipação, propiciando aos participantes o desenvolvimento de diferentes dimensões, bem como o relacionamento de teoria com sua prática e a realização de investigação pedagógica fundamentada em reflexões sobre seu trabalho. $\mathrm{O}$ desenvolvimento de práticas discursivas que acompanham todo esse processo é o fio condutor dessa formação. Isso quer dizer que busco proporcionar oportunidades para que os sujeitos envolvidos possam aprender e desenvolver conhecimentos específicos para sua profissão, tomar decisões de forma consciente e crítica e desenvolver pesquisas como componente constitutivo de sua formação. 
A criação de oportunidades para esse desenvolvimento se dá no processo de ensino e aprendizagem no qual os gêneros textuais se efetivam como artefatos simbólicos para: a inserção dos alunosprofessores (da educação inicial do curso de LEM-LI) em práticas sociais relevantes ao gênero de atividade (docente) (consoante a proposta de Dolz e Schneuwly, 1998) e para o desenvolvimento de práticas discursivas situadas e adequadas. Nesse sentido, ratifico a relação entre agir praxiológico e agir linguageiro (proposta por BRONCKART, 2006; 2008) e/ou saber fazer e saber dizer (proposta por MATÊNCIO, 2008, p. 195):

[...] o saber fazer num certo domínio do conhecimento está vinculado ao processo de inserção do sujeito nesse domínio discursivo, processo pelo qual ele vai construindo um saber dizer, de natureza técnico-científica e, no caso de professores em formação, também de natureza didático-pedagógica.

O saber dizer demanda a aprendizagem de operações de linguagem e o desenvolvimento de capacidades de linguagem que são apresentadas por Dolz, Pasquier e Bronckart (1993, p. 30) como "aptidões requeridas para a realização de um texto numa situação de interação determinada". Considero aptidão a capacidade resultante de conhecimentos primeiramente adquiridos em interação social. As capacidades de linguagem seriam de três tipos: capacidade de ação, capacidade discursiva e capacidade linguístico-discursiva.

A capacidade de ação se constitui pela habilidade do sujeito em construir conhecimentos e/ou representações sobre o contexto de produção de um texto, o que pode contribuir para seu reconhecimento do gênero e sua adequação à situação de comunicação. Já a capacidade discursiva se constitui pela habilidade do sujeito em mobilizar conhecimentos e/ou representações que ele constrói sobre a organização do conteúdo em um texto e sua apresentação. Finalmente, a capacidade linguístico-discursiva se constitui pela habilidade do sujeito em construir conhecimentos e/ou representações sobre as operações e os recursos de linguagem necessários para a produção ou compreensão de um texto. 
Além de considerar as operações e as capacidades de linguagem, é preciso, ainda, destacar que o gênero de atividade (docente) é também tecido por meio de vozes que se diferenciam entre si, de acordo com os valores, os traços e as características de cada um. Essas vozes constituem a identidade do professor.

A concepção de identidade como algo fixo e homogêneo é refutada em favor da noção de identidade como construção multifacetada, fragmentada, complexa e continuamente (re)construída por meio das interações e das atividades linguageiras. "Processos de formação de identidade estão intimamente relacionados aos discursos e às comunidades com as quais trabalhamos" (CLARKE, 2008, p. 9). ${ }^{2}$ De acordo com o autor, os discursos socioculturais e sociopolíticos determinarão quais recursos estão disponíveis para uso no projeto contínuo da construção da identidade, assim como os resultados deste processo, em termos de identidades, por sua vez moldarão/afetarão os padrões discursivos presentes nos diferentes contextos. A linguagem é, portanto, tomada como atividade significativa, dialógica, produtora de sentidos entre indivíduos situados sócio-historicamente.

Assim, a fim de buscar fios da tessitura da identidade do professor em movimentos reconhecíveis na ação de linguagem, características linguístico-discursivas são analisadas - tipo de discurso, escolha lexical, dentre outros aspectos. Para tanto, procuro articular uma abordagem com base em gêneros usada em uma disciplina do curso de Letras em que atuo com a construção de perfil(is) identitários na formação de professores de inglês.

\section{METODOLOGIA}

A experiência com produção escrita de artigo de opinião é parte de um estudo mais amplo sobre gêneros textuais e a construção da identidade profissional em aulas de uma disciplina optativa do curso de Letras Estrangeiras Modernas de uma universidade pública do norte do Paraná, ofertada em 2009. Tal disciplina, denominada "Gêneros Textuais e Ensino de Língua Estrangeira”, tem a seguinte ementa: Conceito de

\footnotetext{
2 "Processes of identity formation are intimately related to the discourses and the communities that we work within.” (CLARKE, 2008, p. 9).
} 
gêneros textuais; Questões epistemológicas e metodológicas (Gêneros e ensino de língua estrangeira; Abordagem de ensino com base em gêneros; Gênero e formação de professores; Procedimentos de análise de gêneros). Objetivos e seleção de gêneros. Transposição didática: as práticas sociais de linguagem como objeto de ensino.

Como o curso é ofertado nos períodos vespertino e noturno, selecionei alunos do noturno, os quais geralmente provêm de escolas públicas e trabalham em tempo integral para estudarem à noite (TÁPIAS-OLIVEIRA, 2005, p. 166), e grande parcela dos professores de línguas é formada em cursos noturnos.

A produção de um texto do gênero artigo é realizada tendo em mente a participação de seus autores na Campanha pela Educação Global $^{3}$ (disponível no site www.campaignforeducation.org), campanha essa que anualmente propõe atividades simultâneas no mundo em uma semana letiva do mês de abril. Em cada ano há uma proposta que explora um tema diferente. No ano 2008, em que a disciplina foi ofertada pela primeira vez, o tema foi "Educação de qualidade para erradicar a exclusão". No ano seguinte foi "Alfabetização de jovens e adultos e aprendizagem ao longo da vida", o qual serviu de base para a produção dos artigos de opinião sob análise neste artigo. Em 2009, o tema foi "Alfabetização de jovens e adultos e aprendizagem ao longo da vida".

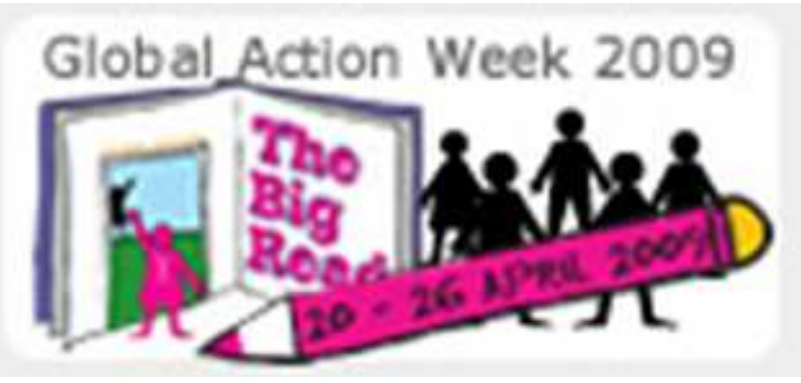

Figura 1 - Campanha Global pela Educação 2009

\footnotetext{
${ }^{3}$ A Semana de Ação Mundial (SAM) é uma iniciativa da Campanha Global pela Educação, e desde 2001 acontece simultaneamente em mais de 100 países como uma grande pressão internacional da sociedade civil sobre líderes e governos para que cumpram os tratados e as leis nacionais e internacionais no sentido de garantir educação pública de qualidade para todas e todos (Manual de Orientações "Ler e escrever o mundo").
} 
Dos onze alunos da turma que participaram da pesquisa, selecionei quatro com base no seguinte critério: realização de 4 produções (produção inicial, refacção 1 , refacção 2, produção final). Assim, o perfil dos alunos cujos textos foram analisados é:

a) Érica: 20 anos, professora de inglês em 2 escolas de idiomas e uma escola de ensino fundamental de um município próximo; participante de projeto de pesquisa em 2008;

b) WGC: 23 anos; auxiliar operacional; participante em projeto de ensino em 2009;

c) Cristina: 21 anos; professora em escola de idiomas; fez oito anos de inglês em uma escola de línguas e dois cursos de inglês no USA; participante de projeto de pesquisa em 2008 e de projeto de ensino em 2009, além de fazer IC (iniciação científica) sem bolsa. Gostaria de trabalhar no Estado por curiosidade;

d) M\&M: 20 anos; monitora em uma escola de línguas; participante de projeto de ensino e de pesquisa em 2009.

A intervenção didática foi planejada com as seguintes etapas:

a) apresentação da situação de comunicação de escrita de artigo de opinião para a participação na campanha global pela educação;

b) produção inicial individual de um artigo de opinião;

c) diagnóstico das dificuldades e do domínio nessa produção de texto;

d) atividades em torno da capacidade de ação;

e) autoavaliação para análise da adequação do texto em relação ao contexto;

f) refacção 1 ;

g) atividades em torno da capacidade discursiva;

h) feedback em pares com comentários acerca da adequação do texto ao contexto e à organização do texto;

i) refacção 2 ;

j) atividades em torno da capacidade linguístico-discursiva; 
k) feedback do professor com comentários acerca da adequação do texto ao contexto, à organização e aos recursos da língua utilizados;

1) produção final;

m) disponibilização do texto.

A figura 2 ilustra o desenho do processo.

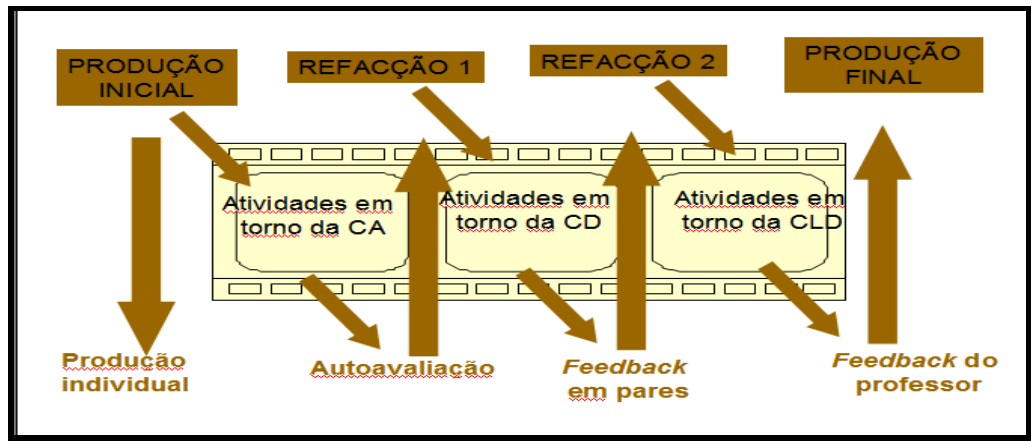

Figura 2 - Esquema do processo de produção escrita numa abordagem baseada em gêneros textuais

\section{RESULTADOS}

Como já apresentado, o propósito subjacente à produção de artigo de opinião foi proporcionar espaços para atividades que se voltam para "debater temas, produzir e compartilhar informações e conhecimentos, realizar ações de mobilização e pressão política [...] pelo direito à educação de qualidade no Brasil" (Manual de Orientações "Ler e escrever o mundo").

Assim, numa concepção de ensino de produção escrita em uma abordagem em torno de gêneros, a proposta didática contemplou características indicadas pela literatura especializada no gênero artigo de opinião.

Como resultado das referências consultadas e das dificuldades a serem superadas a partir do diagnóstico realizado, o esquema a seguir 
ilustra o conteúdo trabalhado e aponta as operações de linguagem necessárias para a produção de artigos de opinião.

\begin{tabular}{|l|l|}
\hline Em relação & $\begin{array}{l}\text { Apresentação da situação de comunicação e participação na aula da } \\
\text { Campanha Global para Educação 2009. }\end{array}$ \\
\hline Ao contexto & $\begin{array}{l}\text { Atenção aos acontecimentos sociais (assunto polêmico/controverso e à } \\
\text { esfera de atuação professional do autor, ao conteúdo temático e à sua } \\
\text { relação com os participantes da interação, aos interlocutors possíveis, ao } \\
\text { meio de veiculaçao, à posição que representa uma esfera social. }\end{array}$ \\
\hline Á organização & $\begin{array}{l}\text { Contextualização da questão a ser discutida; explicitação da premissa; uso de } \\
\text { movimentos arqumentativos para sustentação da posição defendida. }\end{array}$ \\
\hline $\begin{array}{l}\text { Aos recursos } \\
\text { da linguagem }\end{array}$ & $\begin{array}{l}\text { Predomínio do presente do indicativo; pluralidade de vozes, presença de } \\
\text { citações; uso de operadores argumentativos; modelização. }\end{array}$ \\
\hline
\end{tabular}

Figura 3 - Características do gênero textual artigo de opinião

Essas operações de linguagem representam simultaneamente os critérios para analisar os textos dos alunos. Dessa forma, em relação à concepção de artigo de opinião, as atividades partiram da definição de Brakling (2000, p. 226):

[...] um gênero de discurso em que se busca convencer o outro de uma determinada idéia, influenciá-lo, transformar os seus valores por meio de um processo de argumentação a favor de uma determinada posição assumida pelo produtor e de refutação de possíveis opiniões divergentes. É um processo que prevê uma operação constante de sustentação das afirmações realizadas, por meio da apresentação de dados consistentes, que possam convencer o interlocutor.

Uma vez assumida essa definição, a análise objetivou examinar a materialidade discursiva no que diz respeito ao modo como se construiu a intenção de convencer os interlocutores de um ponto de vista baseado em impressões pessoais do autor e em argumentos (coletados sobre o assunto) que fundamentassem a ideia principal. Conforme esses critérios, a análise das quatro produções dos alunos selecionados revelou os seguintes resultados: 


\begin{tabular}{|c|c|c|c|c|}
\hline \multicolumn{2}{|c|}{ Capacidade de ação } & \multirow{2}{*}{$\begin{array}{l}\text { Adequado } \\
(100)\end{array}$} & \multirow{2}{*}{$\begin{array}{l}\text { Parcialmente } \\
\text { Adequado (50) }\end{array}$} & \multirow{2}{*}{$\begin{array}{l}\text { Não } \\
\text { Adequado }(0) \\
\text { X texto dissertativo } \\
\end{array}$} \\
\hline Cristina & $\mathrm{P}$ inicial & & & \\
\hline & Refacção 1 & & $\mathrm{X}$ & \\
\hline & Refacção 2 & & $\mathrm{X}$ & \\
\hline & P final & $\begin{array}{l}\text { X controvérsia mais } \\
\text { clara }\end{array}$ & & \\
\hline \multirow[t]{4}{*}{ Érica } & $\mathrm{P}$ inicial & & & $\mathrm{X}$ texto dissertativo \\
\hline & Refacção 1 & & $\mathrm{X}$ & \\
\hline & Refacção 2 & $\mathrm{X}$ & & \\
\hline & P final & $\mathrm{X}$ & & \\
\hline \multirow[t]{4}{*}{ M\&M } & $\mathrm{P}$ inicial & & & $\begin{array}{l}\text { X Temática não } \\
\text { controversa }\end{array}$ \\
\hline & Refacção 1 & & $\mathrm{X}$ & \\
\hline & Refacção 2 & & $\mathrm{X}$ & \\
\hline & P final & $\mathrm{X}$ & & \\
\hline \multirow[t]{4}{*}{ WGC } & $\mathrm{P}$ inicial & & & $\mathrm{X}$ \\
\hline & Refacção 1 & & $\mathrm{X}$ & \\
\hline & Refacção 2 & $\mathrm{X}$ & & \\
\hline & P final & $\mathrm{X}$ & & \\
\hline
\end{tabular}

Figura 4 - Análise da capacidade de ação nas produções dos alunosprofessores

Quanto à capacidade de ação, a produção inicial de todos revelou a dificuldade de escolher um tema controverso e/ou de dissertar acerca de um tema argumentando, isto é, deixaram de argumentar ou expor um ponto de vista. Com as refacções, a adequação foi sendo ajustada no que diz respeito tanto à temática quanto ao conteúdo veiculado em torno dos argumentos expressos. Com o objetivo de ilustrar esse movimento de adequação, o gráfico 1 ilustra os índices de adequação, adequação parcial e não-adequação nos momentos de Produção Inicial (PI), refacção 1 (R1), refacção 2 (R2) e produção final (PF) dos quatro sujeitos. 


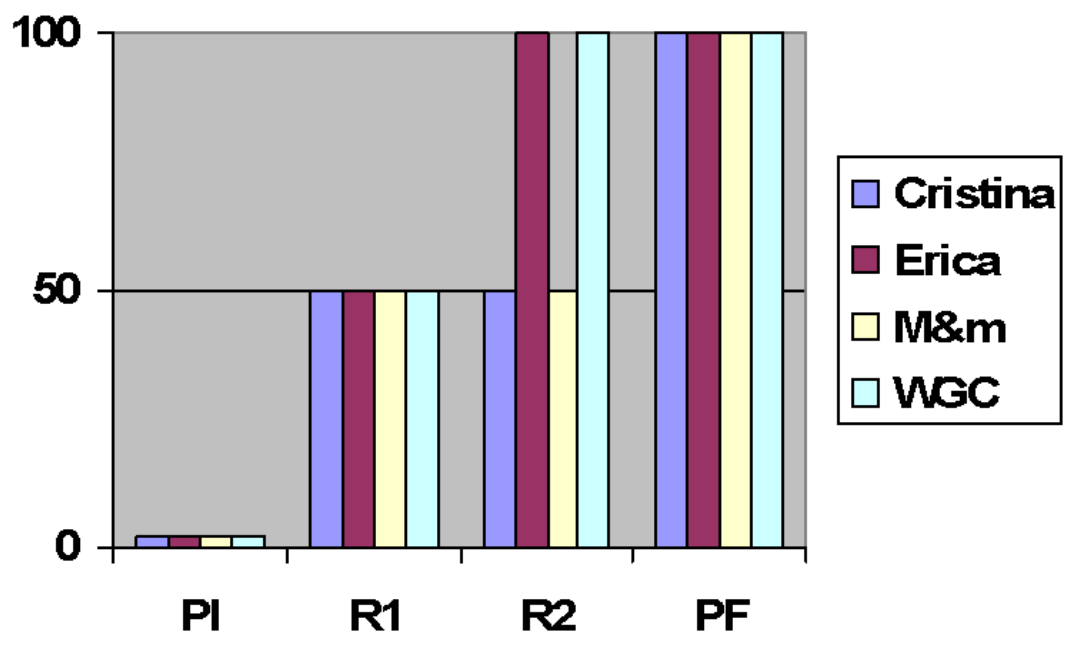

Figura 5 - Adequação referente à capacidade de ação

A principal mudança rumo à adequação observada nos textos foi o esclarecimento do foco em relação à polêmica abordada e à apropriação ao tema. Procurou-se observar pela análise se o texto manifestava atenção aos acontecimentos sociais (assunto polêmico/controverso) e à esfera de atuação profissional do autor; ao conteúdo temático e a sua relação com os participantes da interação; aos interlocutores possíveis; ao meio de veiculação (site da campanha); à posição sustentada que representa uma esfera social - no caso, a formação inicial de professores de língua estrangeira no Brasil. Para dar credibilidade às suas posições, os alunos-professores ancoraram seus textos na produção final em documentos oficiais, em sites específicos ou especialistas da academia para dar suporte ao seu ponto de vista.

Sobre esse último aspecto, a título de exemplo, reproduzo extratos das produções inicial e final de WGC, com marcas de negrito em partes desse tipo de ancoragem. 
The true education

People who are considered literate, sometimes, are not at all.

A person who read a text and can't even understand the author's point of view is not, in my opinion, a literate one. [...] (Initial Production)

Knowledge evaluation in Brazil

The knowledge of people who finished 'ensino médio' in Brazil is not good, and their thoughts ar not critical as the PCNs suggest.

According to statistics from 'Enem', exame nacional do ensino médio (a national sutdent's knowledge exam), in most subjects taught in this period such as: mathematics, chemistry, Portuguese etc, students do not have good knowledge.

I would like to focus on languages which according to the PCNs, Parâmetros curriculares nacionais, should provide different ways of interaction, socialization and critic thinking to contribute to the formation of the citizen. But Portuguese, the official language in Brazil, and English, a foreign language, are not taught according to the PCNs or are not evaluated as they should. People who just left school are generally not able to understand ideological texts and the objective who wrote them.[...] (final production)

Vale destacar que as primeiras atividades realizadas (exemplos são as atividades 2 e 4 abaixo) procuram esclarecer o escopo de um artigo de opinião, o que permite a adequação feita da produção inicial para a final nos extratos do texto de WCG. A seguir, reproduzo as referidas atividades desenvolvidas com os alunos.

Objectives: to learn language operations related to the production of opinion articles

Points of view

$[\ldots]$

2. Choose the best options to complete each sentence:

a. An opinion article is a text that:

() tells a story () presents points of view () shows a piece of news 
b. An opinion article is produced mainly to:

() call readers' attention () make people know about a new fact () discuss a controversial issue

c. We usually find opinion articles in:

() comic books () magazines () recipe books () newspapers.

$[\ldots]$

4. Think about the term "opinion article" and complete the sentence about its objective using the words given: transform - author - position - arguments reader - issue

In an opinion article, the ............. aims to influence the point of view

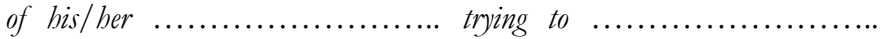
(change, reinforce or weaken) the ..................... or behavior of the readers in relation to the proposed .............. with convincing.....................

(activities 2 and 4 were taken from GEAR UP - Cristovão et al., Curitiba, Base: 2009)

Com relação à capacidade discursiva, as operações de linguagem fundamentais dizem respeito à presença de elementos da argumentação com movimentos argumentativos como:

- Tomada de posição

- Apresentação de argumentos para convencer o leitor

- Consideração pelo ponto de vista dos opositores

- Conclusão, com reforço da posição tomada

Assim, o quadro a seguir expõe o resultado da análise dos textos investigados no que concerne a essa capacidade de linguagem. 


\begin{tabular}{|c|c|c|c|c|}
\hline \multicolumn{2}{|c|}{ Capacidade discursiva } & \multirow{2}{*}{$\begin{array}{l}\text { Adequado } \\
(100)\end{array}$} & \multirow{2}{*}{$\begin{array}{l}\text { Parcialmente } \\
\text { Adequado (50) }\end{array}$} & \multirow{2}{*}{$\begin{array}{l}\text { Não } \\
\text { Adequado (0) } \\
\mathrm{X} \text { - texto } \\
\text { dissertativo - } \\
\text { pouca } \\
\text { sustentação de } \\
\text { argumentos }\end{array}$} \\
\hline Cristina & $P$ inicial & & & \\
\hline & Refacção 1 & & $\mathrm{X}$ & \\
\hline & Refacção 2 & & $\mathrm{X}$ & \\
\hline & P final & $\begin{array}{l}\text { X sustentação de } \\
\text { argumentos (dados, } \\
\text { literatura e exemplos) }\end{array}$ & & \\
\hline \multirow[t]{4}{*}{ Érica } & P inicial & & & $\begin{array}{l}\mathrm{X} \text { não tem } \\
\text { argumentos } \\
\text { Texto } \\
\text { dissertativo } \\
\end{array}$ \\
\hline & Refacção 1 & & & X ensaio \\
\hline & Refacção 2 & & & $\begin{array}{l}\mathrm{X} \text { relatório } \\
\text { técnico }\end{array}$ \\
\hline & P final & & $\begin{array}{l}\text { X contextualiza o tema a ser } \\
\text { discutido e apresenta a } \\
\text { explicitação da posição, } \\
\text { porém não há tempo de } \\
\text { discutir argumentos. }\end{array}$ & \\
\hline \multirow[t]{4}{*}{ M\&M } & P inicial & & $\begin{array}{l}\text { X contextualização e } \\
\text { premissa }\end{array}$ & \\
\hline & Refacção 1 & & $\begin{array}{l}\text { X melhor contextualização, } \\
\text { premissa, argumento parcial }\end{array}$ & \\
\hline & Refacção 2 & $\mathrm{X}$ & & \\
\hline & $P$ final & $\begin{array}{l}\text { X contextualização e } \\
\text { premissa claras com } \\
\text { argumentos e } \\
\text { conclusão com } \\
\text { posição. } \\
\end{array}$ & & \\
\hline \multirow[t]{4}{*}{ WGC } & $P$ inicial & & & $\begin{array}{l}\mathrm{X} \text { texto } \\
\text { dissertativo }\end{array}$ \\
\hline & Refacção 1 & & $\begin{array}{l}\text { X premissa e argumentos, } \\
\text { não há conclusão }\end{array}$ & \\
\hline & Refacção 2 & $\begin{array}{l}\text { X premissa, } \\
\text { argumentos e } \\
\text { conclusão }\end{array}$ & & \\
\hline & P final & $\begin{array}{l}\text { X premissa, } \\
\text { argumentos e } \\
\text { conclusão com posição } \\
\text { do autor }\end{array}$ & & \\
\hline
\end{tabular}

Figura 6 - Análise da capacidade discursiva nas produções dos alunosprofessores 
Em relação à organização, a análise procurou identificar a estrutura com base em Brakling (2000): A tese, argumentos, contraargumentos e conclusão; ou Rodrigues (2005): Agrupamento de vozes para sustentar uma premissa e a desqualificação de vozes opostas; ou Barbosa (2006): "Contextualização da questão a ser discutida; explicitação da posição do articulista; uso de movimentos argumentativos como a sustentação, a negociação, a contraargumentação e a refutação".

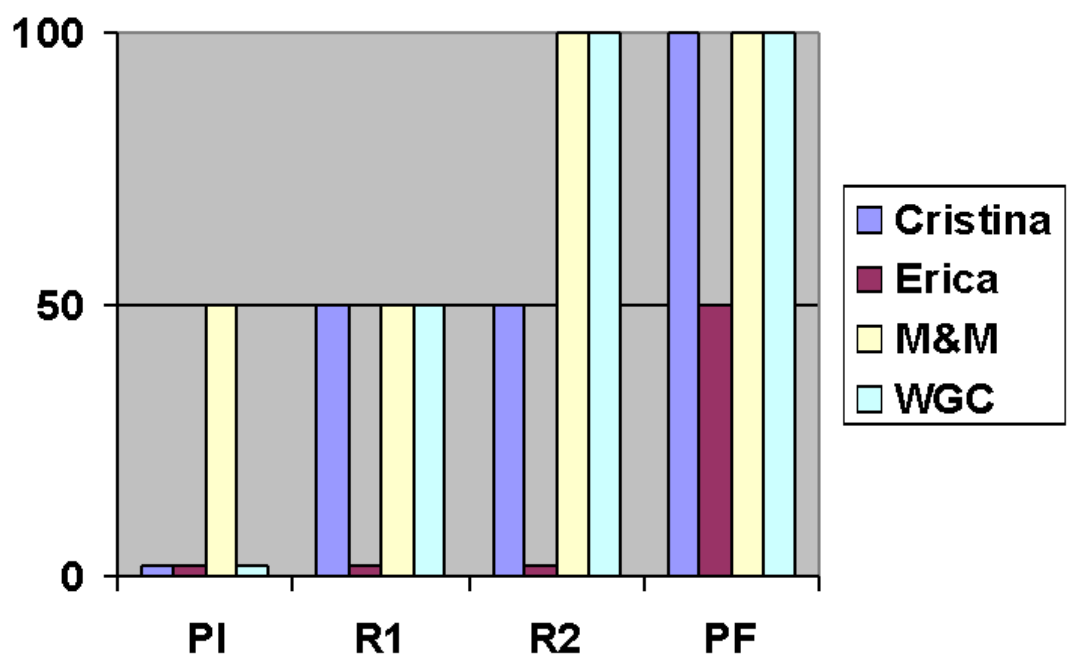

Figura 7 - Adequação referente à capacidade discursiva

Como a figura 7 ilustra, a adequação foi sendo construída, sendo o nível máximo atingido por três dos quatro sujeitos. Além das atividades, a intervenção didática também contou com o uso de uma ficha de avaliação que ia sendo construída conforme o avanço das atividades em torno das capacidades de linguagem. O trabalho de avaliação em pares para nortear a segunda refacção do texto foi orientado pelos itens elencados na referida ficha, apresentada a seguir: 
Evaluate your own article:

1 - Is your article about a controversial issue?

$2-$ Is the issue situated in terms of origin?

3 - Do you express your position?

4 - Do you make use of introductory phrases?

5 - Do you consider different points of view?

6 - Do you use arguments supported by examples, quotes etc?

7 - Do you finish your text by reinforcing your position?

8 - Is the lay-out adequate?

A título de exemplo do movimento de um nível de adequação na organização (item 8 da lista), reproduzo extratos das produções inicial e final de Érica. Chamo a atenção para o uso do pronome de primeira pessoa do plural na produção inicial e primeira pessoa do singular na final para indicar a tomada de posição (item 3 da lista) e sua implicação com uso de dêiticos de pessoa (item 7 da lista).

$[\ldots]$

The view of education for people, who missed the school and the right time to study, is a good opportunity for ones that really did not have conditions to afford it. But as we see, with the inclusion of teens at these programs, the problem was born in another context. (Initial Production)

$[\ldots]$

Prioritizing programs to illiterate people out of the regular scholar age, I consider, it is not the most efficient solution, for a problem that is too far from this. People can be accommodated having the conscience that future programs will guarantee them learning if they miss primary education. (Final Production) 
No que concerne à capacidade linguístico-discursiva, mais especificamente aos recursos da linguagem, a análise procurou identificar o uso de terceira pessoa; predomínio do presente do indicativo; pluralidade de vozes, presença de citações, uso de operadores argumentativos; uso de grupos proposicionais do discurso citado; discurso relatado indireto e modalização.

\begin{tabular}{|c|c|c|c|c|}
\hline $\begin{array}{l}\text { Capacidade } \\
\text { linguístico- } \\
\text { discursiva }\end{array}$ & & $\mathrm{AD}$ & PAD & NAD \\
\hline \multirow[t]{4}{*}{ Cristina } & $\mathrm{P}$ inicial & & $\mathrm{x}$ & \\
\hline & Refacção 1 & & $\mathrm{x}$ & \\
\hline & Refacção 2 & & $\mathrm{x}$ & \\
\hline & $\mathrm{P}$ final & & $\mathrm{x}$ & \\
\hline \multirow[t]{4}{*}{ Érica } & $\mathrm{P}$ inicial & & $\mathrm{x}$ & \\
\hline & Refacção 1 & & $\mathrm{X}$ & \\
\hline & Refacção 2 & & $X$ & \\
\hline & $\mathrm{P}$ final & & $\mathrm{x}$ & \\
\hline \multirow[t]{4}{*}{$\mathrm{M} \& \mathrm{M}$} & P inicial & $\mathrm{X}$ & & \\
\hline & Refacção 1 & $X$ & & \\
\hline & Refacção 2 & $X$ & & \\
\hline & $\mathrm{P}$ final & $\mathrm{X}$ & & \\
\hline \multirow[t]{4}{*}{ WGC } & $\mathrm{P}$ inicial & & $\mathrm{X}$ & \\
\hline & Refacção 1 & & $X$ & \\
\hline & Refacção 2 & & $X$ & \\
\hline & $\mathrm{P}$ final & & $\mathrm{x}$ & \\
\hline
\end{tabular}

Figura 8 - Análise da capacidade linguístico-discursiva nas produções dos alunos-professores

Quanto às operações de linguagem relativas à capacidade linguístico-discursiva, procurou-se examinar a presença ou a ausência de expressões (para indicar tomada de posição) e o uso (não) adequado dos recursos da língua em textos escritos. 


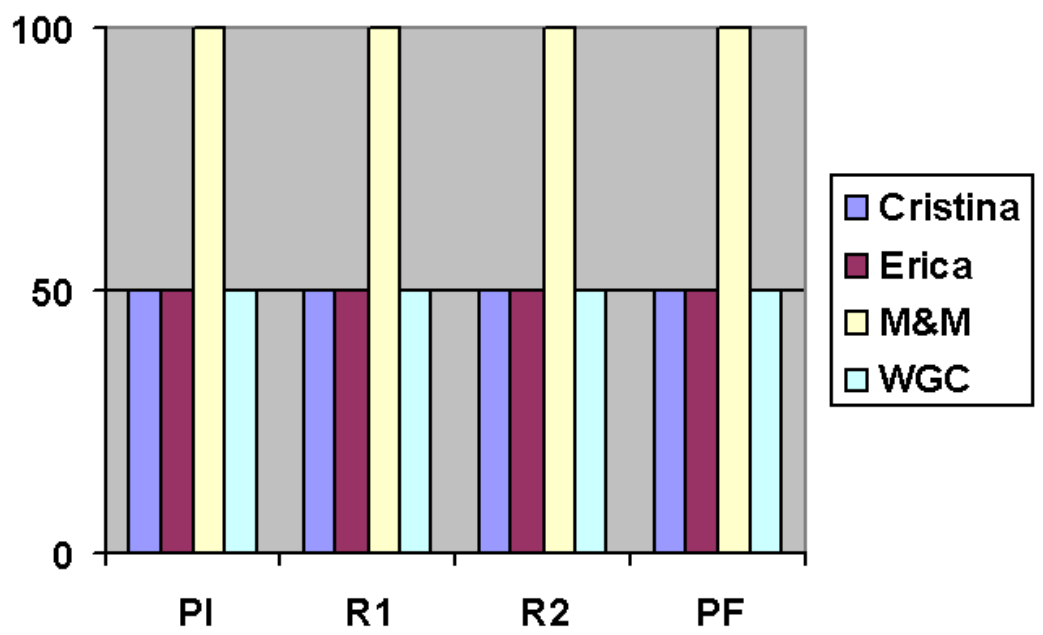

Figura 9 - Adequação referente à capacidade linguístico-discursiva

A produção escrita de artigo de opinião em uma abordagem com base em gênero não parece ter afetado a melhora nesse nível de proficiência. As dificuldades com aspectos lexicogramaticais gerais não sofreram modificações relevantes ao longo do processo para apurar a produção escrita desses futuros professores, permanecendo praticamente as mesmas.

Como se pode notar do exposto até o momento, o trabalho de (re)construção do artigo de opinião demonstra o processo de aprendizagem dessa prática discursiva. As operações de linguagem realizadas com maior adequação têm relação prioritária com as capacidades de ação e discursiva. O agir do aluno-professor contemplou uma busca a referências; uma relação entre teoria e prática e a mobilização de dimensões diversas do trabalho docente.

Perseguindo nosso outro objetivo, o de investigar o(s) perfil(is) de profissional que se constrói(em) (discursivamente) nos textos analisados, podemos reconhecer diferentes dimensões do trabalho do professor evidenciadas pelas atividades e pelas produções realizadas pelos participantes da pesquisa, conforme discutido na sequência. 
O processo descrito e analisado está articulado ao processo de (re)construção da identidade profissional. Com alicerce nessas considerações acerca da relação entre gêneros textuais e formação de professores, discutimos brevemente como se constitui o gênero de atividade pela construção das dimensões do trabalho docente articulada ao processo de produção escrita em uma abordagem com base em gêneros.

Os alunos-professores vivenciam um procedimento metodológico de ensino de produção escrita com base em gêneros, ao mesmo tempo que realizam uma prática discursiva como futuros profissionais da educação e cidadãos do mundo. Essa meta-aprendizagem em relação ao processo de produção escrita e em relação ao processo de ensino/aprendizagem representa uma oportunidade de construção das dimensões didática, social, prescritiva e profissional. Tanto no plano epistemológico quanto no praxiológico, os alunos tiveram no gênero um instrumento para as bases da comunicação, que lhes permitiram agir com a linguagem na situação enfocada. Assim, as dimensões profissional, artística e identitária foram mobilizadas para a definição tanto do tema quanto do conteúdo a veicular e do ponto de vista a ser sustentado. Para apropriação desse instrumento, os alunos-professores aumentaram seus conhecimentos a fim de agir sobre o outro, mobilizando as dimensões cognitiva e renormalizadora. A aprendizagem de produção de artigos de opinião pôde representar desenvolvimento pessoal e profissional do professor.

Em suma, o gênero textual, como artefato simbólico, está à disposição do sujeito para ser apropriado e construído como um instrumento para atingir os objetivos de sua ação. Tanto a apropriação quanto as ações dela decorrentes surtem mudanças interiores que provocam o desenvolvimento individual, cuja repercussão atinge o nível social. Nesse nível, posso tanto citar o grupo de alunos quanto o contexto maior da campanha que se beneficiaria com a circulação de textos sobre a educação de jovens e adultos no Brasil.

Posso afirmar que a produção escrita de um artigo de opinião, cujo pressuposto já é a de emissão de um ponto de vista, demandou reflexão sobre práticas educacionais e a formação profissional. Embora a vivência acadêmica com a escrita de artigo de opinião tenha sido curta e restrita, a oportunidade de conhecer e criticar uma atividade profissional 
docente (nesse caso, a educação de jovens e adultos) pôde interferir na sua construção identitária.

Os alunos futuros professores escolheram fazer seus textos com pouca implicação por meio do baixo uso de dêiticos de pessoa e priorizaram o tipo de discurso teórico. O discurso teórico, do eixo do expor, não tem implicação dos parâmetros materiais da ação de linguagem, ou seja, há maior distanciamento entre os interactantes. A ausência de dêiticos parece pretender produzir posicionamento distanciado e uma pretensa objetividade cuja construção parece dar ênfase à verdade das asserções e ao mascaramento da subjetividade. Essa característica, que torna o texto mais autônomo, parece ter sido influenciada pela necessidade de trazer vozes que sustentem a premissa defendida, principalmente argumentos de autoridade ou de exemplificação. O discurso teórico é comumente planificado por fases da sequência explicativa, argumentativa ou descritiva.

Essa estratégia pode ter sido fortemente influenciada por uma das perguntas da ficha de avaliação diagnóstica de escrita do gênero artigo de opinião usada em seu processo de refacção, a saber, se o autor sustentava seus argumentos com exemplos, citações etc..

Esses resultados, que apontam para a baixa implicação do autor, parecem relacionar-se à construção de um professor genérico sem marcas de individualidade. Os movimentos argumentativos mobilizados pretendem ancorar a voz do professor que quer ser reconhecido pelo seu fazer profissional por meio de dados e/ou citações da literatura da área.

\section{CONSIDERAÇÕES FINAIS}

Considerando o primeiro objetivo exposto no início deste artigo, a comparação dos resultados dos índices de adequação das diferentes versões do gênero artigo de opinião (com base nas características do gênero apresentadas pelos participantes), pude expor que houve desenvolvimento nas capacidades de linguagem com operações de linguagem, ainda que insatisfatoriamente melhoradas.

No que tange ao segundo objetivo, o que as produções textuais puderam mostrar é que o processo de aprendizagem de uma atividade linguageira específica (produção escrita de um artigo de opinião) levou os 
alunos-professores a confrontar tanto seus conhecimentos de língua quanto seus saberes sobre uma situação profissional específica. Com base na análise realizada, o processo de produção escrita vivenciada resultou em um domínio parcial do gênero enfocado, bem como na constituição de identidades tecidas nas dimensões motivacionais, intencionais e de recursos ancoradas majoritariamente naquelas de origem coletiva e socialmente validadas.

Voltando ao título - "Gêneros textuais e educação inicial do professor de língua inglesa” -, a prática social de produção escrita de artigo de opinião proporcionou a aprendizagem de operações de linguagem necessárias ao agir no mundo enfocado pelo gênero textual: colaborar para a formação da opinião pública e persuadi-la em favor de uma determinada posição assumida pelo produtor. Por outro lado, apesar de o gênero artigo de opinião pretender se constituir como um espaço para que o produtor faça uso de sua voz e seja capaz de produzir significados, os segmentos linguísticos dominantes fazem emergir um discurso generalizante, ancorado ora no discurso acadêmico, ora em orientações/dados oficiais.

Essa característica parece escancarar a necessidade de incluir, de forma mais intensa e frequente, gêneros textuais que possibilitem maior implicação e apropriação dos argumentos usados que acarretariam formas de textualização da referência pessoal, considerando as necessidades imediatas do contexto educacional desse aluno futuro professor. Dessa forma, a educação inicial ampliaria o espaço no qual o próprio aluno futuro professor seria o actante com capacidades, motivos e intenções, ou seja, ator que, segundo Bronckart e Machado (2004), intervém no agir.

\section{REFERÊNCIAS}

ALMEIDA FILHO, J.C.P. Crises, transições e mudança no currículo de formação de professores de línguas. In: FORTKAMP, M. B. M.; TOMITCH, L. B. M. (Orgs.) Aspectos da lingüística aplicada: estudos em homenagem ao Professor Hilário Inácio Bohn. Florianópolis: Insular, 2000. p. 33-47.

AMIGUES, R. Trabalho do professor e trabalho de ensino. In: MACHADO, A. R. (Org.). $O$ ensino como trabalho: uma abordagem discursiva. Londrina: Eduel, 2004. p. 37-53. 
BORGHI, C.I.B. A configuração do trabalho real do professor de língua inglesa em seu próprio dizer. Dissertação (Mestrado em Estudos da Linguagem)-Universidade Estadual de Londrina, Londrina, 2006.

BRAKLING, K. L. Trabalhando com artigos de opinião: re-visitando o eu no exercício da (re)significação da palavra do outro. In: ROJO, R.H. (Org.). A prática de linguagem em sala de aula: praticando os PCNs. Campinas: Mercado de Letras, 2000. p. 221-247.

BRASIL. Ministério da Educação e Cultura. Conselho Nacional de Educação. "Resolução de 18 de fevereiro de 2002". Diário Oficial da União, 9 abr. 2002.

BRONCKART, J.P. Atividade de linguagem, discurso e desenvolvimento humano. MACHADO, A. R.; MATENCIO, M. L. M. (Orgs.). Campinas: Mercado de Letras, 2006. (Coleção Ideias sobre a Linguagem)

. O agir nos discursos: das concepções teóricas às concepções dos trabalhadores. MACHADO, A. R.; MATENCIO, M. L. M. (Orgs.). Campinas: Mercado de Letras, 2008. (Coleção Ideias sobre a Linguagem)

BRONCKART, J. P.; MACHADO, A. R. Procedimentos de análise de textos sobre o trabalho educacional. In: MACHADO, A.R. (Org.). O ensino como trabalho: uma abordagem discursiva. Londrina: EDUEL, 2004. p. 131-163.

CAMARGO, G. P. de Q. P. de. Análise de um exame internacional como instrumento de avaliação do conhecimento sobre ensinar do professor de inglês. Dissertação (Mestrado em Estudos da Linguagem)-Universidade Estadual de Londrina, 2007.

CAMPBELL, N. Developing effective writing through genre awareness. In: KETTERMANN, B.; MARKO, G (Orgs.) Expanding circles, transcending disciplines and multimodal texts: reflections on teaching, learning and researching in English and American studies. Tubingen: Gunther Narr Verlarg, 2003. p. 19-26.

CANALE, M.; SWAIN, M. Theoretical bases of communicative approaches to second language teaching and testing. Applied Linguistics, n. 1, p. 1-47, 1980.

CLARKE, M. Language teacher identities: Co-constructing discourse and community. Clevedon: Multilingual Matters, 2008. (New Perspectives on Language \& Education)

DOLZ, J.; PASQUIER, A.; BRONCKART, J.P. L'acquisition des discours: émergence d'une compétence ou apprentissage de capacités langagières? ÉLA Études de Linguistique Appliquée, n. 92, p. 23-37, 1993. 
DOLZ, J.; SCHNEUWLY, B. Pour un enseignement de l'oral. Initiation aux genres formels à l'école. Paris : ESF ÉDITEUR, 1998. (Didactique du Français).

DOLZ, J.; NOVERRAZ, M.; SCHNEUWLY, B. Seqüências didáticas para o oral e a escrita: apresentação de um procedimento. In: ROJO, R.; CORDEIRO, G. S. (Orgs. e tradutoras). Gêneros orais e escritos na escola. São Paulo: Mercado de Letras, 2004. p. 95-128.

FREEMAN, D.; JOHNSON, K. Reconceptualizing the knowledge-base of language teacher education.Tesol Quarterly, v. 32, n. 3, 1998.

GIMENEZ, T.; CRISTOVÃO, V. L. L. Derrubando paredes e construindo pontes: formação de professores de inglês na atualidade. Revista Brasileira de Lingüística Aplicada, v. 5, n. 2, p. 85-95, 2004.

GUIMARÃES, A. M. M.; MACHADO, A.R.; COUTINHO, A. (Orgs.) O Interacionismo Sociodiscursivo: questões epistemológicas e metodológicas. Campinas: Mercado de Letras, 2007. (Coleção Ideias sobre a Linguagem)

KLEIMAN, A. B.; MATENCIO, M.L.M. (Orgs.) Letramento e formação do professor: práticas discursivas, representações e construção do saber. Campinas: Mercado de Letras, 2005. (Coleção Ideias sobre a Linguagem)

Ler e escrever o mundo. Manual de Orientações e Propostas de Atividades. Disponível em: <www.campanhaeducacao.net>. Acesso em: 5 abr. 2009.

LEFFA, V.J. Aspectos políticos da formação do professor de línguas estrangeiras. In: O professor de línguas estrangeiras: construindo a profissão. 2. ed. Pelotas: EDUCAT, 2006. p. 353-376.

MACHADO, A.R. (Org.) O ensino como trabalho: uma abordagem discursiva. Londrina: EDUEL, 2004.

MACHADO, A. R.; CRISTOVAO, V. L. L. O agir do professor em documentos institucionais brasileiros para a formação inicial. In: CONGRESSO INTERNACIONAL EDUCAÇÃO E TRABALHO: Representações sociais, competências e trajectórias profissionais, 2005, Aveiro. Anais... Aveiro: Universidade de Aveiro, 2005.

MACHADO, L. A. Institucionalização da lógica das competências no Brasil. Pro-Posições, v. 13. n.1 (37), jan./abr. 2002.

MATENCIO, M. L. M. Gêneros discursivos na formação de professores: reflexões sobre a construção de saberes e o processo de letramento. In: GIL, G.; VIEIRA-ABRAHÃO, M. H. Educação de professores de línguas: os desafios do formador. Campinas: Pontes Editores, 2008, p. 189-199. 
NUNES, C. S. C; MONTEIRO, A. L.; SANTOS, T. R. L.; TÁVORA, M. J. S. ; CUNHA, E. R. Pedagogia das competências como política de formação de professores no Brasil. CONGRESSO INTERNACIONAL EDUCAÇÃO E TRABALHO: Representações sociais, competências e trajectórias profissionais, 2005, Aveiro. Anais... Aveiro: Universidade de Aveiro, 2005.

PERRENOUD, p. Formar professores em contextos sociais em mudança prática reflexiva e participação crítica. Revista Brasileira de Educação, Rio de Janeiro, n. 12, p. 5-19, set./nov. 1999.

PLACCO, V.M.N.S. Os saberes necessários ao trabalho do professor. In: CONGRESSO INTERNACIONAL EDUCAÇÃO E TRABALHO:

Representações sociais, competências e trajectórias profissionais, 2005, Aveiro. Anais... Aveiro: Universidade de Aveiro, 2005.

Perspectivas e dimensões da formação e do trabalho do professor. In: SILVA, A.M.M. et al. (Org.) Educação formal e não-formal, processos formativos, saberes pedagógicos: desafios para a inclusão social. Recife: ENDIPE, 2006. p. 251-261.

RICHARDS, J. C. Beyond training. Cambridge: Cambridge University, 1998.

RODRIGUES, R.H. Os gêneros do discurso na perspectiva dialógica da linguagem: a abordagem de Bakthin. In: MEURER, J.L; BONINI, A. MOTTAROTH, D. (Orgs.). Gêneros: teorias, métodos, debates. São Paulo: Parábola Editorial, 2005. p. 152-183.

ROSSI, E. C. S. A construção do conhecimento e da identidade do professor de inglês. 2004. Dissertação (Mestrado em estudos da Linguagem)Universidade Estadual de Londrina, Londrina, 2004.

SAUJAT, F. O trabalho do professor nas pesquisas em educação: um panorama. In: MACHADO, A. R. (Org.). O ensino como trabalho: uma abordagem discursiva. Londrina: EdUEL, 2004.

SHULMAN, L. S. Those who understand: knowledge growth in teaching. Educational Researcher, v. 15, n.2, 1986.

. Knowledge and teaching: foundations of the new reform. Harvard Educational Review, v. 57, n. 1, 1987.

SOUZA-E-SILVA, M. C. P. O ensino como trabalho. In: MACHADO, A. R. O ensino como trabalho: uma abordagem discursiva. Londrina: EDUEL, 2004. p. 81-104. 
TÁPIAS-OLIVEIRA, E. M. A construção da identidade profissional do professor e sua produção diarista. In: KLEIMAN, A.; MATENCIO, M.L.M.

(Orgs.) Letramento e formação do professor: práticas discursivas, representações e construção do saber. Campinas: Mercado de Letras, 2005. p. 165-180.

TARDIF, M. Le transfert des compétences analysé à travers la formation de professionnels. Lyon: Conférence dans le cadre du Colloque International sur le Transfert des Connaissances. 1994.

. Saberes docentes e formação profissional. Petrópolis: Vozes, 2002.

Recebido em 30/08/2010. Aprovado em 31/01/2011.

Title: Text genres and English pre-service teacher education.

Author: Vera Lúcia Lopes Cristovão

Abstract: According to the theoretical and methodological assumptions of the sociodiscursive interactionism (BRONCKART, MACHADO, 2004; BRONCKART, 2006; GUIMARAES, MACHADO, COUTINHO, 2007), the relevance of the studies on text genres for pre-service teacher education is based on its role for the production of socially and bistorically situated values and forms of action. The groups of texts (belonging to different text genres, which circulate in the scope of pre-service teacher education represent a net of discourses that also help to constitute the professional genre (activity genre) of the teacher to be. These text genres are textualized in different ways in this social activity sphere (BRONCKART, 2006). So, this work intends to a) analyze the characteristics of the opinion articles produced by teachers to be and b) investigate the professional profile(s) that are discursively constructed in the analyzed corpus. The results indicate there was relative mastering of the genre representing important space for reflection on the sphere of the chosen professional activity.

Keywords: Text genre. Pre-service teacher education. Opinion article.

Titulo: Géneros textuales y educación inicial del profesor de lengua inglesa

Autor: Vera Lúcia Lopes Cristovão

Resumen: De acuerdo con los supuestos teórico-metodológicos del interacionismo sociodiscursivo BRONCKART, MACHADO, 2004; BRONCKART, 2006; GUIMARÃES, MACHADO, COUTINHO, 2007), la relevancia de los estudios de géneros para la educación inicial está en el hecho de ser productores de valores y de formas de actuar socio-históricamente situados. Los conjuntos de textos (de diferentes géneros textuales), que circulan en la formación inicial, se configuran em una red de discursos que ayudan a tejer el género profesional docente y, de alguna forma, contribuyen para el aprendizaje profesional del futuro profesor. Esos géneros textuales se textualizan de diferentes modos en esa esfera de la actividad social (BRONCKART, 2006). Asi, esta pesquisa se propuso (a) analizar las características de articulos de opinión producidos por futuros profesores y b) investigar el(los) perfilles) de profesional que se construye(n) discursivamente en los textos analisados. Los resultados apuntan para un dominio relativamente bajo del género, pero representan importante espacio para reflexión sobre la esfera de actividad profesional elegida.

Palabras-clave: Géneros textuales. Educación inicial de profesores. Artículo de opinión.

CRISTÓVÃO - Gêneros textuais e educação inicial... 